\title{
$40 \mathrm{GHz}$ small-signal cross-gain modulation in $1.3 \mu \mathrm{m}$ quantum dot semiconductor optical amplifiers
}

Cite as: Appl. Phys. Lett. 93, 051110 (2008); https://doi.org/10.1063/1.2969060

Submitted: 10 June 2008 • Accepted: 18 July 2008 • Published Online: 06 August 2008

C. Meuer, J. Kim, M. Laemmlin, et al.

\section{ARTICLES YOU MAY BE INTERESTED IN}

Role of carrier reservoirs on the slow phase recovery of quantum dot semiconductor optical amplifiers

Applied Physics Letters 94, 041112 (2009); https://doi.org/10.1063/1.3073715

25 Gbit/s differential phase-shift-keying signal generation using directly modulated quantum-dot semiconductor optical amplifiers

Applied Physics Letters 106, 213501 (2015); https://doi.org/10.1063/1.4921785

Phase noise and jitter reduction by optical feedback on passively mode-locked quantumdot lasers

Applied Physics Letters 103, 231101 (2013); https://doi.org/10.1063/1.4837716

四 QBLOX

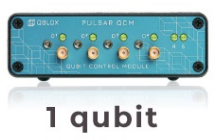

Shorten Setup Time Auto-Calibration More Qubits

Fully-integrated Quantum Control Stacks Ultrastable DC to $18.5 \mathrm{GHz}$ Synchronized $<<1 \mathrm{~ns}$ ultralow noise

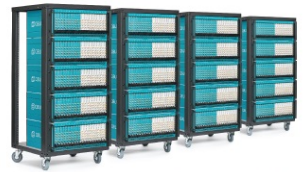

100s qubits

visit our website > 


\title{
$40 \mathrm{GHz}$ small-signal cross-gain modulation in $1.3 \mu \mathrm{m}$ quantum dot semiconductor optical amplifiers
}

\author{
C. Meuer ${ }^{1, a)}$ J. Kim, ${ }^{1, b)}$ M. Laemmlin, ${ }^{1}$ S. Liebich, ${ }_{4}^{1}$ D. Bimberg, ${ }^{1}$ A. Capua, ${ }^{2}$ G. Eisenstein, ${ }^{2}$ \\ R. Bonk, ${ }^{3}$ T. Vallaitis, ${ }^{3}$ J. Leuthold, ${ }^{3}$ A. R. Kovsh, ${ }^{4}$ and I. L. Krestnikov ${ }^{4}$ \\ ${ }^{1}$ Institut fuer Festkoerperphysik, Technische Universitaet Berlin, EW 5-2, Hardenbergstr. 36, 10623 Berlin, \\ Germany \\ ${ }^{2}$ Electrical Engineering Department, Technion, Haifa 32000, Israel \\ ${ }^{3}$ Institut fuer Hochfrequenztechnik und Quantenelektronik, Universitaet Karlsruhe, Engesserstr. 5, 76131 \\ Karlsruhe, Germany \\ ${ }^{4}$ Innolume GmbH, Konrad-Adenauer-Allee 11, 44263 Dortmund, Germany
}

(Received 10 June 2008; accepted 18 July 2008; published online 6 August 2008)

\begin{abstract}
Small-signal cross-gain modulation of quantum dot based semiconductor optical amplifiers (QD SOAs), having a dot-in-a-well structure, is presented, demonstrating superiority for ultrahigh bit rate wavelength conversion. Optimization of the QD SOA high speed characteristics via bias current and optical pump power is presented and a small-signal $3 \mathrm{~dB}$ bandwidth exceeding $40 \mathrm{GHz}$ is demonstrated. The $p$-doped samples investigated here enable small-signal wavelength conversion within a range of $30 \mathrm{~nm}$, limited mainly by the gain bandwidth. (C) 2008 American Institute of Physics. [DOI: 10.1063/1.2969060]
\end{abstract}

GaAs based quantum dot based semiconductor optical amplifiers (QD SOAs) operating in the $1.3 \mu \mathrm{m}$ wavelength range $^{1,2}$ are decisive components for future all optical high speed communication networks, e.g., the $100 \mathrm{Gbit} / \mathrm{s}$ Ethernet. QD SOAs offer several attractive characteristics for such applications, the most important being a wide gain spectrum resulting from inhomogeneous gain broadening ${ }^{3}$ and ultrafast carrier dynamics. ${ }^{4,5}$ The inhomogeneous broadening is responsible for complex cross saturation dynamics. ${ }^{6}$ QDs of different sizes, whose ground state (GS) energies are not within the homogeneously broadened gain, are only indirectly coupled via the common carrier reservoir of higher energy states. These states are located in the surrounding quantum well (QW) (dot-in-a-well structure) and bulk materials. The excited states (ESs) and the carrier reservoir refill the GS after depletion. ${ }^{6}$ The time constants for carrier relaxation between and within these levels range from 130 fs for the ES to the $\mathrm{GS}^{4}$ relaxation to several hundred picosecond recovery and relaxation of QW after depletion. ${ }^{7}$ The ultrafast QD dynamics enable large saturation power as well as pattern effect free amplification of fast signals under saturated conditions, ${ }^{8-10}$ as has been shown at $1.55 \mu \mathrm{m}$. Ultrafast nonlinear applications such as wavelength conversion by efficient cross-gain modulation (XGM) are feasible. Smallsignal $\mathrm{XGM}^{11}$ and wavelength conversion of short pulses ${ }^{12}$ at $1.55 \mu \mathrm{m}$ as well as $40 \mathrm{Gbit} / \mathrm{s}$ data ${ }^{13}$ conversion at $1.3 \mu \mathrm{m}$ have already been demonstrated. However, no systematic study of the XGM frequency response dependent on the operating parameters in InGaAs QD SOAs at $1.3 \mu \mathrm{m}$ has been reported.

An $\mathrm{Al}_{0.35} \mathrm{Ga}_{0.65} \mathrm{As} / \mathrm{GaAs}$ waveguide structure with ten layers of InAs QDs in a GaAs core was grown by molecular beam epitaxy. The QDs are covered by an $\operatorname{In}_{0.15} \mathrm{Ga}_{0.85} \mathrm{As} \mathrm{QW}$ layer to extend the emission wavelength to $1.3 \mu \mathrm{m} .{ }^{14} \mathrm{~A} 33$

\footnotetext{
${ }^{a)}$ Electronic mail: chmeuer@sol.physik.tu-berlin.de.

${ }^{b}$ Present address: Department of Information Display, Kyung Hee University, Seoul 130-701, Korea.
}

$\mathrm{nm}$ thick GaAs $p$-doped spacer separating the QD layers ensures strain relaxation.

Ridge waveguide QD SOA structures of $4 \mu \mathrm{m}$ width were cleaved to $2 \mathrm{~mm}$ long SOAs. The ridge was dry etched through the active core layer containing the QDs to provide strong index guiding of the optical mode and to suppress current spreading. The waveguides are tilted at $6.8^{\circ}$ and antireflection coated. The QD SOAs were fiber coupled using tapered fibers with a measured loss of $4 \mathrm{~dB}$ per facet. The maximum linear chip gain and saturation output power were $19 \mathrm{~dB}$ and $+14 \mathrm{~dB}$ m, respectively. This corresponds to a chip saturation input power of $-2 \mathrm{~dB}$. The residual gain ripple was smaller than $2 \mathrm{~dB}$.

We performed small-signal XGM measurements ${ }^{15}$ using an HP $8722 \mathrm{C}$ network analyzer (NA). The setup is shown in Fig. 1. A saturating pump signal from a $1311 \mathrm{~nm}$ distributed feedback (DFB) laser diode is externally modulated by a small sinusoidal signal. The pump is injected into the QD SOA together with a $\mathrm{cw}$ probe signal from a wavelength tunable external cavity laser (ECL). The ECL signal probes the gain spectrum and experiences the modulation via XGM. The pump is filtered at the SOA output using a fiber Bragg grating and a tunable filter. The probe is detected and its modulation characteristics are analyzed by the NA. The elec-

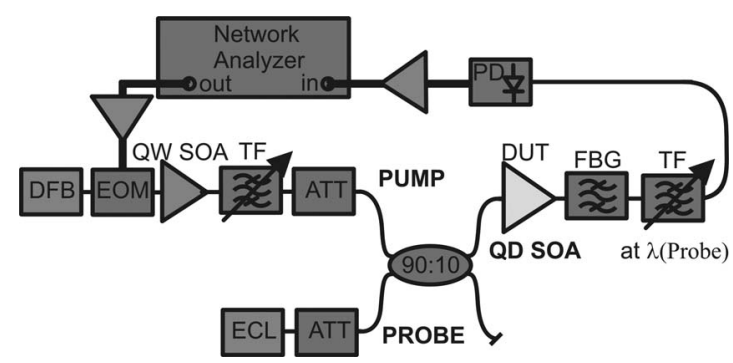

FIG. 1. Experimental schematic for small-signal XGM measurement: EOM electro-optical modulator; QW SOA, quantum well semiconductor optical amplifier; ATT, attenuator; ECL, external cavity laser; FBG, fiber Bragg grating; DUT, device under test (QD SOA); TF, tunable filter; and PD, photodetector. 


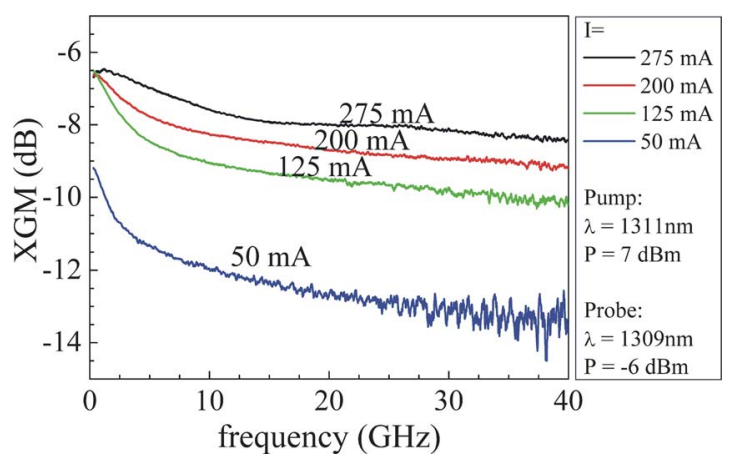

FIG. 2. (Color online) Normalized XGM response for various drive currents.

trical $S_{21}$ parameter is transformed to units of optical power and normalized to the response of the pump without the QD SOA called XGM efficiency.

The dependence of the XGM on the drive current is shown in Fig. 2. The general shape comprises a strong decrease up to around $10 \mathrm{GHz}$, which is related to the slow dynamics of the carrier reservoir in the higher energy states. The nearly flat region ranging from 10 to $40 \mathrm{GHz}$ is attributed to the fast dynamics of the QDs because the carrier reservoir of the higher energy states cannot respond at these high frequencies. At a low current of $50 \mathrm{~mA}$ the XGM bandwidth is limited to $12 \mathrm{GHz}$, which is comparable to the XGM results known from QW SOAs ${ }^{16,17}$ where bandwidths only up to $30 \mathrm{GHz}$ and a weak current dependence were found. However, at currents larger than $200 \mathrm{~mA}$ the QD SOA XGM is significantly enhanced and the $3 \mathrm{~dB}$ bandwidth exceeds 40 GHz. The reservoir becomes highly populated at large currents, enabling fast recovery of the QD states while the change of the carrier density and distribution is negligible. Therefore, spectral hole burning with its ultrafast recovery becomes the dominant saturation mechanism. This is possible due to the small density of states in the QD GS and the energy separation from the carrier reservoir and enables to circumvent the slow dynamics after depletion of the carrier reservoir in the QW. Thus, by increasing the current the dominating saturation mechanism can be changed from slow carrier depletion to ultrafast spectral hole burning and hence the XGM bandwidth can be tuned from 10 to beyond 40 $\mathrm{GHz}$. On the contrary, QW or bulk SOAs do not have a separate carrier reservoir due to larger and continuous density of states such that the enhancement of XGM bandwidth induced by spectral hole burning is not significant at large injection current. ${ }^{16}$

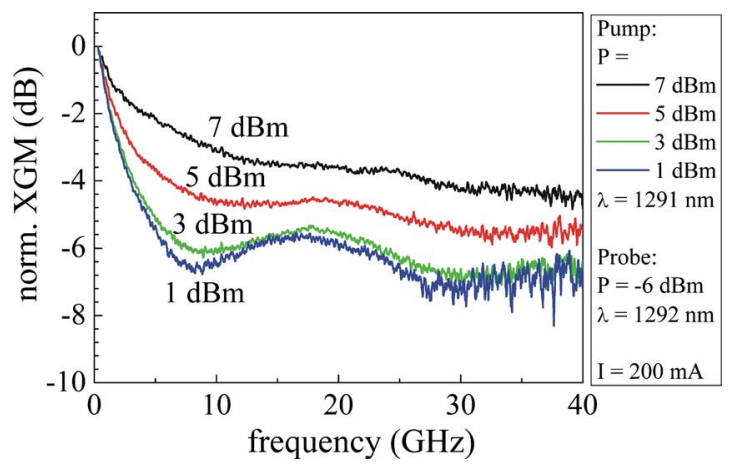

FIG. 3. (Color online) Normalized XGM for different pump power levels.

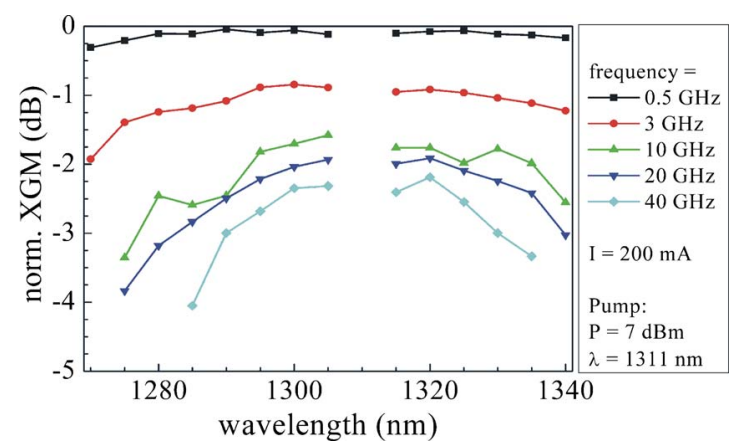

FIG. 4. (Color online) Normalized XGM dependence on wavelength for various modulation frequencies.

The input pump power level also influences the XGM, as shown in Fig. 3. Starting from $1 \mathrm{dBm}$ (which is above the 3 $\mathrm{dB}$ saturation input power) and up to $+7 \mathrm{dBm}$, the normalized XGM enhances significantly by reduction in the low frequency drop. This results from the enhanced gain saturation due to spectral hole burning. The absolute efficiency decreases due to the increasing gain saturation. The overall conversion efficiency is currently limited to $-8 \mathrm{~dB}$. This could be enhanced with larger gain QD SOAs.

The wavelength dependence of the XGM for various modulation frequencies is depicted in Fig. 4. Here, the XGM traces are additionally normalized to their respective maximum. At frequencies below $3 \mathrm{GHz}$ the wavelength dependence is mainly determined by the gain spectrum and therefore appears as a flat line after normalization. This can be explained by depletion of the carrier reservoir that feeds carriers to all the QD subensembles. Hence, its depletion causes broadband XGM similar to QW SOAs. ${ }^{16}$ For a smallsignal modulation in the gigahertz regime, a wavelength dependence especially at high frequencies (above $30 \mathrm{GHz}$ ) is observed. The QD subensembles are only indirectly coupled via the carrier reservoir and therefore high speed XGM due to spectral hole burning can only occur within a spectrally narrowband range determined by the homogeneous linewidth. However, for a large detuning outside the homogeneous width, carrier depletion causes XGM but is much less efficient at high frequencies than spectral hole burning.

The dominance of spectral hole burning makes QD SOAs superior compared to QW or bulk devices and indicates that $p$-doped QD SOAs are suitable for broadband $( \pm 15 \mathrm{~nm})$ high speed wavelength conversion mainly limited by the $3 \mathrm{~dB}$ gain bandwidth.

In conclusion, we have reported ultrafast small-signal XGM of $1.3 \mu \mathrm{m}$ GaAs based QD SOAs. Dependent on the bias current, the $3 \mathrm{~dB}$ bandwidth can be tuned from 12 to more than $40 \mathrm{GHz}$. The XGM exhibits a wavelength dependence due to spectral hole burning especially at high frequencies. The separation of the carrier and the QD GS enables the dominance of spectral hole burning over carrier depletion and therefore high speed XGM superior to conventional QW or bulk devices. This makes QD SOAs promising candidates for wavelength conversion in future all optical networks. Detailed large signal wavelength conversion experiments at high data rates have yet to be performed, which could be affected by patterning caused by the slow dynamics of the QW. 
The authors acknowledge funding by the SANDiE NoE of the European Commission Contract No. NMP4-CT-2004500101, the TRIUMPH Project No. IST-027638 STP, the Marie Curie Fellowship MIF1-CT-2006-040250, the State of Berlin (ProFIT MonoPic and OptiDot), and the Sonderforschungsbereich SFB 787 of the German Research Council. G. Eisenstein is a Humboldt awardee at TU Berlin and thanks the Humboldt Foundation for its support.

${ }^{1}$ D. Bimberg, Electron. Lett. 44, 168 (2008).

${ }^{2}$ D. Bimberg, M. Kuntz, and M. Laemmlin, Microelectron. J. 36, 175 (2005).

${ }^{3}$ D. Bimberg, N. Kirstaedter, N. N. Ledentsov, Zh. I. Alferov, P. S. Kop'ev, and V. M. Ustinov, IEEE J. Sel. Top. Quantum Electron. 3, 196 (1997).

${ }^{4}$ P. Borri, W. Langbein, J. M. Hvam, F. Heinrichsdorff, H.-M. Mao, and D. Bimberg, IEEE J. Sel. Top. Quantum Electron. 6, 544 (2000).

${ }^{5}$ S. Dommers, V. V. Temnov, U. Woggon, J. Gomis, J. Martinez-Pastor, M. Laemmlin, and D. Bimberg, Appl. Phys. Lett. 90, 033508 (2007).

${ }^{6}$ J. Kim, M. Laemmlin, C. Meuer, G. Eisenstein, and D. Bimberg, IEEE J. Quantum Electron. 44, 658 (2008).

${ }^{7}$ T. Vallaitis, C. Koos, R. Bonk, W. Freude, M. Laemmlin, C. Meuer, D. Bimberg, and J. Leuthold, Opt. Express 16, 170 (2008).
${ }^{8}$ A. V. Uskov, T. W. Berg, and J. Mork, IEEE J. Quantum Electron. 40, 306 (2004)

${ }^{9}$ T. Akiyama, M. Ekawa, M. Sugawara, K. Kawaguchi, H. Sudo, A. Kuramata, H. Ebe, and Y. Arakawa, IEEE Photonics Technol. Lett. 17, 1614 (2005)

${ }^{10}$ A. V. Uskov, E. P. O'Reilly, M. Laemmlin, N. N. Ledentsov, and D. Bimberg, Opt. Commun. 248, 211 (2005).

${ }^{11}$ J. Kim and S. L. Chuang, IEEE Photonics Technol. Lett. 18, 2538 (2006).

${ }^{12}$ A. Bilenca, R. Alizon, V. Mikhelashvili, D. Dahan, G. Eisenstein, R. Schwertberger, D. Gold, J. P. Reithmaier, and A. Forchel, IEEE Photonics Technol. Lett. 15, 563 (2003).

${ }^{13}$ T. Akiyama, N. Hatori, Y. Nakata, H. Ebe, and M. Sugawara, Phys. Status Solidi B 238, 301 (2003).

${ }^{14}$ A. R. Kovsh, N. A. Maleev, A. E. Zhukov, S. S. Mikhrin, A. P. Vasil'ev, E. A. Semenova, Yu. M. Shernyakov, M. V. Maximov, D. A. Livshits, V. M. Ustinov, N. N. Ledentsov, D. Bimberg, and Zh. I. Alferov, J. Cryst. Growth 251, 729 (2003).

${ }^{15}$ R. Alizon, A. Bilenca, H. Dery, V. Mikhelashvili, G. Eisenstein, R. Schwertberger, D. Gold, J. P. Reithmaier, and A. Forchel, Appl. Phys. Lett. 82, 4660 (2003).

${ }^{16}$ T. Durhuus, B. Mikkelsen, C. Joergensen, S. L. Danielsen, and K. E. Stubkjaer, J. Lightwave Technol. 14, 942 (1996).

${ }^{17}$ C. Joergensen, S. L. Danielsen, K. E. Stubkjaer, M. Schilling, K. Daub, P. Doussiere, F. Pommerau, P. B. Hansen, H. N. Poulsen, A. Kloch, M. Vaa, B. Mikkelsen, E. Lach, G. Laube, W. Idler, and K. Wunstel, IEEE J. Sel. Top. Quantum Electron. 3, 1168 (1997). 